\title{
English as an Alien Language: Teachers' Experiences of the English Across the Curriculum Strategy in South Africa
}

\author{
Lokesh Ramnath Maharajh $^{1}$, Bongani Chilli ${ }^{1,2}$ \\ ${ }^{1}$ School of Education, University of KwaZulu-Natal \\ ${ }^{2}$ Qwabe Secondary School \\ South Africa
}

\begin{abstract}
English Across the Curriculum (EAC) is introduced to learners in many rural schools perform below the expected level. This study adopted a qualitative research approach to explore teachers' experiences of the EAC strategy in rural secondary schools. Purposive sampling was used to select three teachers from each school in three respective circuit management centers (CMCs). Employing qualitative interviews as the data collection method, we found that the EAC strategy's key issues are learners' inability to use English, teachers' inability to use English, learners' home environment, and lack of communication of the DBE's commitment. We believe that teachers should be afforded the necessary scaffolding to familiarize themselves with the target language. The DBE should gear up its management regimens to capacitate, monitor, and evaluate teachers using the EAC strategy. In the interest of our country's democratic dispensation, it would be desirable to grant learners the opportunity to learn their indigenous language. This study will afford researchers of the EAC an understanding of the intricacies of fostering English teaching across the curriculum from the perspective of teachers.
\end{abstract}

\section{Introduction}

The English Across the Curriculum Strategy "every teacher is a language teacher" [1], [2]. Teachers in South African schools are expected to use the English Across the Curriculum (EAC) strategy in the classroom since the language of learning and teaching (LoLT) used is key to understanding the subject content in a school [1]. What happens if teachers are not well versed in the language of instruction? [3] stated that when teachers' second language (L2) knowledge is not acceptable for using English as a LoLT, their low usage and understanding of the language are transferred to their learners. It is correct to say that language is the core aspect of many independent cognitive, affective, and social factors shaping learning and thinking [4]. Without a proper understanding of the language of instruction, it is virtually impossible to grasp the subject content, leading to academic failure.

The EAC strategy was introduced in South Africa when Grade 12 results were so poor, especially in the rural provinces, that it became a cause for concern for the whole ministry of education. This led to the private sector stepping in to help bridge the gap between rural and urban schools [5]. The idea behind the EAC is to familiarize learners with the necessary English language concepts, vocabulary, and conventions that are essential for understanding content subjects. [6] defined EAC as the use of the target language (e.g., English) as a medium of instruction to teach content subjects, improve the teaching of the target language and prepare students to expand their knowledge through the target language. The EAC strategy was introduced to address poor academic performance among learners whose mother tongue is not English. Provinces highlighted as performing poorly were Limpopo, the Eastern Cape, and KwaZulu-Natal. These provinces have a significant number of rural schools, and the high rate of failure was attributed to the high number of rural secondary schools. There was a concern that most examination candidates do not understand examination questions well because of low English language proficiency. The Department of Education then came up with the EAC strategy to promote mastery of English as a medium of instruction [7]; [8]. [7] conducted a study to explore how high school teachers deal with the infusion of content and language, and they came up with these two main pedagogical approaches: (1) intentional disciplinary language learning, which refers to the deliberate study of subject-specific language skills through planned learning activities, and (2) incidental disciplinary language acquisition, which refers to the learning of disciplinary language in the context of everyday interaction within the class and school contexts.

According to [9], of the country's 23,000 public schools, 11,252 were in rural areas. The majority of these schools were in the Eastern Cape, KwaZuluNatal, and Limpopo. One can conclude that the lack of prevalence of English in rural areas is the cause of 
the poor academic results among rural secondary school learners.

One of the authors has been a teacher of English since 2011. Working with learners whose home language is not English has been daunting. As an English language teacher, it was always mandatory to use English. However, each time he used English exclusively, learners would complain that they did not understand what was being said. He even tried to include more teaching aids and gestures to help his learners understand. Since this was time-consuming, he could not finish the lesson within the stipulated time, affecting curriculum coverage. The difficulty in learners understanding English is the same challenge that content subject teachers face when teaching these subjects through English. [10] the study focused on science teachers' experiences teaching English second language learners in English. The study revealed that teachers had to code-switch into the learners' home language throughout the lesson. Teachers of English are strongly discouraged from teaching using the learners' vernacular [11]; [12]. Furthermore, at all English First Additional Language (EFAL) workshops, subject advisors argue that learners will never learn a second language through the medium of their home language.

There have been occasions when one of the authors has reverted to using the learners' home language in his teaching. From anecdotal information, we know that this is true of other teachers in neighboring schools. The literature, too, reports on teachers code-switching [13]; [14]; [15]; [12]; [16]. [12] reported that teachers in his study presented their lessons in English and some codeswitching to Xhosa to achieve a range of cognitive and linguistic aims. This is confirmed by [13]. He suggested that teachers play a leading role in allowing learners to employ code-switching, which serves as a strategy to promote linguistic and cultural diversity in multilingual communities. In a study conducted by [16], teachers code-switched in the Afrikaans L2 class, partly because of their incompetence and partly because learners did not understand when only Afrikaans was spoken in the classroom. This indicates that code-switching may be regarded as a survival tool where learners have difficulty understanding subject content when a second language is used. As [17] puts it, the ability to code-switch is an important tool for the individual in the learning process in the context of a multilingual and multicultural society.

A preliminary literature review revealed that previous research studies had been conducted on the EAC strategy [18]; [19]; [20]. However, these studies have not directly explored teachers' realities when EAC is used with non-English Home Language users. [20] focused on teachers' reading experiences and found that teachers used codeswitching to facilitate learners' reading. [19] and
[18] addressed teachers' challenges in teaching English as a subject. They found that teacher development activities, training courses, and a collaborative learning environment could provide teachers with the necessary expertise to teach English as a subject. However, none of these studies dealt directly with the experiences of applying the EAC strategy.

Therefore, we were motivated to conduct a study to explore teachers' experiences of the EAC strategy. In particular, we wanted to conduct this study in rural secondary schools since one of the authors has been teaching in rural secondary schools for 20 years now. Teachers are the ones who have a direct encounter with the teaching and learning situation, and their input in any curriculum strategy is vital to explore teachers' ideas and inputs on the teaching of EAC.

The study covers the three circuit management centres (CMC) of the ILembe district. These are Maphumulo, Stanger, and Ndwedwe CMCs. Maphumulo schools are $100 \%$ rural, whereas some parts of Stanger and Ndwedwe schools are urban. The focus of this study was on rural secondary schools of the ILembe District. ILembe District comprises four local municipalities: Ndwedwe, Mandeni, Maphumulo, and KwaDukuza. It is situated on the east coast of KwaZulu-Natal along the Indian Ocean. ILembe District is the smallest of all KZN District municipalities, and it contains, to a more considerable extent, rural tribal authorities' areas. Illiteracy characterises in these tribal authority areas and unemployment rate are high. Most of the families survive on social grants and subsistence farming. During the past years, the Department of Education embarked on a wide scale launching of Adult Basic Education, but this did not bear fruit due to the lack of commitment by those to whom this was intended. This is the summary of Education statistics in the ILembe District:

$\begin{array}{ll}\text { No schooling: } & 11 \% \\ \text { Matric: } & 32.8 \% \\ \text { Higher education: } & 6.3 \% \\ \text { School drop-out: } & 49.9 \%\end{array}$

This situation poses a problem for the school-going children since they hardly get the necessary support with their schoolwork since their parents and older siblings are not well educated. This may lead to learners' lackadaisical attitude towards schooling and subsequent dropping out. The predominant language of communication in these rural areas is IsiZulu. The school-going children only encounter the English language at school, where English is taught both as a subject and as a medium of instruction 
Use of the indigenous language dominates the rural communities. All their communication, rituals, and ceremonies are performed using the indigenous language. In terms of this study, Zulu is the dominant language in our rural areas in KwaZulu-Natal. You will hardly find a rural community member conversing in English. [21] argued that children from rural areas experience English language problems because they do not use English outside school. At school, English is used for teaching and assessment. Many of these rural school learners have to grapple with the language used for questioning before attempting to figure out what the examiners want for them to answer a question. Against this scenario, teachers have to strictly communicate learning content to the learners in English and teach English across the curriculum [1]. Comprehension is critical, as it fosters analysis, critique, evaluation, and synthesis of information from various sources [22]. When learners write essays in content subjects, such as History, they rely mostly on memorization. If they forget a single word or phrase, they get stuck and leave the rest of the essay undone. This is called regurgitation or rote learning. Questions presented to learners in the form of scenarios appear to be very difficult for them; they instead want questions to be direct, so they can relate them to what they have crammed in their memories. Even if a learner can accurately recall all the information stored in their memory, many of them do not, in essence, understand the content thereof. If required to cascade this information to others, they find it difficult to do so, even in their mother tongue. If learners cannot interact with or critique the knowledge they have assimilated, they cannot implement it. Implementation of experience, or transfer of learning, is the ultimate aim of all learning. Transfer of learning can be defined as applying what one has learned in a particular situation to another situation in a different context [23]. Therefore, understanding the language of instruction is crucial to learning. The question is how teachers face applying the EAC strategy, given the poor understanding of English in rural communities. This study may serve as an eyeopener to policymakers regarding the viability of the EAC strategy in rural secondary schools, and it may promote further engagement with the strategy among policymakers and stakeholders, with the view to possibly restrategizing.

In the sections that follow, we present a review of selected literature on EAC, paying particular attention to EAC's potential problems and complexities and strategies to implement EAC. We then briefly discuss the theory of collaboration, arguing that the success of EAC depends on collaboration between language teachers and content subject teachers. In the methodology section, we present a discussion of the research approach (qualitative research), the research paradigm (the interpretive paradigm), the research style (case studies), and the data generation method (interviews). The findings section of this paper presents participants' understanding of the EAC strategy and the reasons for the non-implementation of EAC. The reasons cited include learners' inability to use English, teachers' inability to express themselves properly in English, learners' home environment, and lack of commitment from the Department of Education (DoE). The discussion section presents the themes that emerged from the findings. We conclude the paper with recommendations and suggestions for further research.

\section{Literature Review}

A curriculum is a multifaceted concept constructed, negotiated, and renegotiated at various levels and in a variety of arenas [24]. The curriculum has been described as a multifaceted process involving many elements. [25] defined curriculum as a concept consisting of various elements, such as (a) goals and objectives (the curriculum intent), (b) content or subject and subject matter, (c) learning experiences, and (d) evaluation. [26] accurately defined curriculum to embrace all the facets of school learning thus:

The curriculum is all the selected, organized, integrative, innovative, and evaluative educational experiences provided to learners consciously or unconsciously under the school authority to achieve the designated learning outcomes which are achieved as a result of growth, maturation, and learning meant to be best utilized for life in a changing society. The curriculum is not just a physical thing but the interaction of teachers, students, and knowledge [26], [27], [28]. This means that curriculum is a broad concept that can be viewed differently. Trying to describe a curriculum from a single perspective could be counterproductive. It is interesting to note how [24] brings the idea of construction, negotiation, and renegotiation to the fore. Put, the curriculum is carefully constructed to meet certain objectives, and it is negotiated with various stakeholders at different levels not just once but repeatedly until a consensus has been reached. [29] affirmed that curriculum is an umbrella term that includes many issues: teaching curriculum, learning curriculum, testing curriculum, administrative curriculum, and hidden curriculum.

For this study, curriculum refers to the courses of study or content. It refers specifically to five streams of subjects that prevail in most secondary schools. These streams are Languages, Commerce, Sciences, and Humanities. 


\section{Meaning of Experiences}

Experiences can be defined in a variety of ways and from different perspectives. Wikipedia dictionary defines experiences in three ways; the processes through which conscious organisms perceive the world around them, as practical contact and observation of facts or events, and as events or occurrences which leave an impression on someone. The word 'perceive' refers to acquiring knowledge using five senses of touch, smell, sight, hearing, and taste, while practical contact and observation irrevocably mean involvement with reality for an extended period.

Collins's Dictionary defines experiences as knowledge and skills in a particular job or activity you have gained because you have done the job or activity for a long time or past events, knowledge, and feelings that make someone's life or character.

Lastly, the Merriam Webster Dictionary defines experiences as direct observation or participation in events as a basis of knowledge or the fact or state of having gained knowledge through direct observation or participation, as practical knowledge, skills or practices derived from direct observation of or participation in events or a particular activity, and, as something personally encountered or lived through.

The definitions by Wikipedia and Merriam Webster Dictionaries capture the use of the term in this study. Participants in this study had to be teachers who have been involved with teaching and learning for quite a long period, who have had an opportunity to practically engage and observe learners' attitudes and behaviours concerning the EAC strategy. There are six aspects of experiences, emotional aspect, intellectual aspect, religious aspect, social aspect, virtual aspect, and perceptual aspect:

i. Emotional aspect - involves something that personally touches an individual positively or negatively, i.e., falling in love for the first time or losing your loved one.

ii. Intellectual aspect - entails a person's ability to think and understand things. This means that a person can make meaning out of their own experiences.

iii. Religious aspect - involves aspects of faith and spirituality, e.g., being initiated in a certain religion or spirituality

iv. Social aspect - A human being is a social being, meaning that an individual find meaning and expression in the context of a society. [30] stated that growing up and living in a society can foster the development and observation of social experience. v. Virtual aspect - involves the use of computers to access knowledge. [31] stated that computer simulations could enable a person or group of people to have a virtual experience.

vi. Perceptual aspect - the word 'perception' is derived from Latin 'perception', which means gathering or receiving. It also means organizing, identifying, and interpreting sensory information to represent information or the environment.

Our study used 'experiences' to incorporate perceptual, social, and intellectual aspects:

- Perceptual aspect - Participants in this study were people who have observed their behaviours and heard their responses in connection with teachers' use of the EAC strategy through constant and continuous engagement with learners.

- Social aspect - The participants in this study were teachers who have, for most of their time, engaged and interacted with learners and teachers in a variety of situations to correctly and authentically garner information about their response to the strategy.

- Intellectual aspect - The participants in this study had to apply their thinking and meaning making strategies to correctly identify and interpret information gleaned through social and perceptual engagement with learning and teaching.

\section{English language position during apartheid South Africa}

The arrival of White missionaries during the seventeenth and eighteenth centuries brought about a new dawn in the lifestyle of African people. Concomitant with the teaching of the good news about Jesus Christ was introducing mission schools so that young people to read the Bible. Since these missionaries did not know indigenous languages well, they used $100 \%$ English language as a medium of instruction, to which their learners became accustomed. Although the missionaries had learned IsiZulu to convert the Zulu population to Christianity, they taught in English rather than promoting the Zulu language and culture, regarded as inferior [32]. Even learners' names were changed to be easy for teachers to call them. According to [33], this was the first step towards altering their self-concept. Missionary schools were later taken over and regulated by the South African government. Almost in every school, speaking English during the official teaching hours was not just a necessity but an imperative. According to [32], before the Union of 
South Africa, the Zulu people in the Kingdom of KwaZulu, south of the Thukela River, received education through English.

Schools instituted various mechanisms for fostering the use of English. One of the prevalent mechanisms at that time was the card method. The card used to be given the perfect for giving it to the first offenders, who would then pass the same to others. All learners identified to have held the offender's card were punished mainly through corporal punishment. However, since not all teachers and schools committed themselves fully in the drive to use English only was not always successful.

\section{English language in post-apartheid South Africa}

The political regime changes in South Africa after 1994 went hand in hand with changes in language policy [34]. In 1994 the new South African government led by the African National Congress came into being, and the new constitution was drafted and passed in 1996. The language issue was never omitted. According to the S.A. constitution, act No. 104 of 1996, all official languages have equal status. All measures to enforce the use of English during official school hours were relaxed since such attempts would be tantamount to the violation of the constitution. Without the pressure to use English at school, many learners did not dare practice it for their benefit in mastering the subject content. [35] contends that lack of comprehension adversely affects academic performance. To work around the problem of comprehension, teachers use codeswitching, which is not favoured by the EAC strategy. Using an explorative research study [36] found that $48 \%$ of her study participants strongly agreed that being taught in a home language and English made it easy to understand. This explains that code-switching has, to a greater extent, a beneficial effect on learning. Code-switching in the classroom may lead to a better understanding and communication for ELoLT learners and prevent communication breakdowns between teachers and learners [33]. [37] affirmed that given learners' limited grasp of English, it is inevitable that teachers will resort to a mixture of languages for clarification and explication.

The most common strategy used by teachers to assist learners with comprehension of subject matter is code-switching and code-mixing. According to [38], code-switching refers to the switching from one language to another over phrases or sentences, whereas, on the other hand, code-mixing is the switching of individual words from one language to another in one utterance [39]. However, according to the EAC strategy, this is not permissible. [40] interestingly put it thus:
"Official policy says that English should be used as the medium of instruction in secondary school classrooms throughout South Africa, but very often, informal policy prescribes that teacher use students' home language (which is not English) to supposedly facilitate the teaching process learning."

This kind of situation could be caused by some teachers' command of the language of instruction is not good enough or learners' grasp of subject content being affected by a lack of second language comprehension. According to [41], many teachers do not know how to teach English as a subject, nor can they speak well enough to be effective role models of the language. He adds that the children must interact with people who know the language, since, as [42] puts it, if the learner cannot understand the language of instruction, it becomes difficult, if not impossible, to grasp the content of the subject.

\section{The role of language in the acquisition of academic content}

Language determines our being, and it is vital to our continued existence. From the pre-natal stage, a foetus starts expressing its needs to the mother, but during this time, communication is a sign language. [43] accurately defined language thus:

\begin{abstract}
"Language is at the centre of human life. It is one of the most important ways of expressing our love or hatred for people; it is vital to achieving many of our goals and careers; it is a source of artistic satisfaction or simple pleasure."
\end{abstract}

The EAC strategy is based on the idea that learning and comprehension of subject content would be facilitated if used with language skills. According to [44], content-based language teaching is an approach to second language instruction that involves using a second language to learn or practice content. [45] stated earlier that integration of language and content instruction was intended to develop second language skills and academic concepts because this focuses on meaning rather than form. However, [33] think that it is emotionally demanding for ELolT learners to acquire cognitive academic language proficiency (CALP) and to master academic content at the same pace as English first language (L1) learners. It remains unclear how long it takes a learner to master the language of instruction to comprehend academic content. [42] warns that if the learner cannot understand the language of instruction, it becomes difficult, if not impossible, to grasp the content of the subject. It is important to be cognisant that comprehension is at the heart of knowledge acquisition. According to [35], lack of comprehension adversely affects 
academic performance. Children organize their world through language and try to create a reasonable fit between their present capabilities to understand and communicate this understanding [46]. When children go to school, they bring their language, cultural and environmental backgrounds. It is incumbent upon teachers to align their teaching accordingly to experience school as an extension of the home. [47] clearly illustrated the connection between the learners' home culture and the school culture, thus:

"Children learn to communicate in the
context of their home culture.
Beginning at birth, children use their
home language and culturally
accepted communication styles to
connect with others in a meaningful
way, forming secure relationships
intrinsic to healthy development. For
the early childhood teacher, it is
important to establish supportive,
respectful relationships with both
families and children. These
connections help teachers learn more
about every child's strength, needs
and culture in their care."

[48] affirmed that all children bring to the learning process their ways of interpreting the natural and social worlds acquired from their cultural environments, discursive traditions, and personal circumstances. Teachers are responsible for building upon what learners have already acquired in the home, and they should, as far as possible, refrain from creating confusion between the school and the home. However, there is a great chasm between the school and the home in terms of language and culture in a rural community setting.

In South African schools, instruction or academic language is English. This, I think, creates some confusion in the mind of a child whose mother language is not English and who lives in the traditional African communities. Consequently, as [49] states, programmes desiring to help young learners master two languages need to be built on the philosophy based on the meshing of language with everyday social relationships. This means that language is not taught in a vacuum. It must be aligned and infused with every day-to-day experience of learners.

In most cases, English language textbooks do not sufficiently reflect rural life experiences. So, it is important that when teaching learners in a rural context, teachers tailor-make their English language lessons to accommodate them. [50] state that all languages occur within a particular environment. According to [51], language, culture and environment are interrelated. Learners interact with their culture and environment through their language. [52] affirmed that language is integral to the culture and cultural processes. Without language, no culture transfer between generations is possible, as parents or caregivers communicate to their children the cultural values that underlie language [33]. Language is the medium through which groups preserve their innate cultures and keep their traditions alive [53]. The preceding illustrates the complexities involved in teaching English across the curriculum.

This means that we can only express our culture through language, oral or written. [54] once stated that culture is almost indistinguishable from the language that makes possible its genesis, growth, banking, articulation, and transmission from one generation to the next. (Ngugi Wa Thiong'o of Kenya was the most powerful and influential writer of African literature. He is known for promoting the use of mother languages in African literature). He further concluded that language, as culture, was the collective memory bank of a people's experience in history. Language, therefore, determines our historical roots, that is, where we came from. According to [54] the idea of teaching English across the curriculum in rural settings cannot be pedagogically conducive to learners.

A lot has been discussed about the teaching of English across the curriculum and how this poses a challenge to rural school learners whose home language is IsiZulu. In the following section, I focus on teachers' role in mediating knowledge to their learners.

\section{English Across the Curriculum (EAC)}

EAC is a strategy for integrating the teaching of content subjects with language learning [1]. This means that every teacher, not just the English teachers, should be a language teacher to be well prepared to carry out this mammoth task. [55] stated that English language literacy is essential for success in all subjects and that it cannot be the sole responsibility of the English teachers. [55] added that mastery of the language of instruction is essential for developing skills fundamental for school success and critical thinking.

Various authors have conducted studies on teachers' experiences of EAC. According to the findings of most studies, teachers generally agree to use EAC as something good for learners' education [56]; [57]; [58]; [59]. Studies also indicate that no matter how good the EAC strategy could be, it is not without potential problems and complexities [60]; [61]; [58]; [62].

In the following section, we explore teachers' experiences of English Across the Curriculum based on the reviewed literature under the following headings: (a) recognition of EAC; (b) potential problems and difficulties related to EAC; (c) 
teachers' perceived strategies; and (d) the role of teacher training institutions and the Department of Education.

\section{Recognition and acceptance of EAC}

As highlighted in most studies, teachers seem to favor the teaching of English across the curriculum. [58] conducted a study to explore teachers' perceptions of English as a learning and teaching language. Employing questionnaire surveys, open interviews, and classroom observation, she found that teachers regarded English as a language of learning and teaching favorably. Teachers understand and acknowledge the role of English in the education of children because English is a global language [63] and, as [64] stated, it remains the dominant language of business and politics.

[59] explored language in education from the perspective of secondary school subject teachers in Finland. Using interviews as the data collection method, they found that teachers were reasonably aware of their field's subject-specific language (English) and the value of multiliteracy practices. In other words, although teachers recognized the use of English as a medium of instruction, they also valued the preservation of learners' home languages. It is important that, while recognizing the teaching of English across the curriculum, learners' home languages are not neglected. However, EAC also brings with it problems and complexities.

\section{Potential problems and complexities}

Drawing from a study conducted by [58], teachers highlighted inherent complexities within the EAC strategy. These complexities are learners' minimal exposure to English outside school [60], English being a second language, lack of training in the teaching of EAC [61], lack of familiarity with balancing language and content [62], and learners' negative attitude toward English [60].

Learners, especially in rural schools, do not have sufficient access to the school language after school hours. Most parents and other adult members in rural areas are functionally illiterate and have no media resources, such as libraries. Parents' illiteracy poses a problem for learners' academic performance. [65] argued that children whose parents did not complete school or had poor literacy skills are more likely to be functionally illiterate themselves. For most South Africans, English is a second language. English is used as a medium of instruction in most South African schools, challenging English second language learners. [66] stated that using language for learning can be difficult for people educated in a second language. [42] Many poor and working-class children whose mother tongue is not English go through 12 years of schooling and still struggle with
English. [42] This is because they have received little practice in the language at home due to parents' or caregivers' illiteracy in English or their mother tongue. Since English is the language of learning and teaching (LoLT), it is emotionally demanding for English second language learners to acquire cognitive academic language proficiency and master academic content at the same pace as English first language learners [33].

Teachers' perceived low English language proficiency is another complexity related to EAC. [67] sought to investigate current pedagogical practices engaged in by teachers from different cultural backgrounds when using English as a medium of instruction and how their practices affect learners' knowledge of English. This study revealed low English language proficiency among the teachers, which resulted in them making grammatical errors, mispronunciation, and incorrect spellings during lessons. The results of this study also seem to suggest that one has to be a native speaker of English to be able to teach learners fluently, as when the teacher's first language is not English, they may unknowingly pronounce words with an accent, which may result in the wrong intonation, which learners may adopt.

Teachers' training to use EAC is a complexity revealed by [61]. He alludes to teachers' lack of teaching English across the curriculum. The EAC strategy has not been in existence for very long in South Africa. Consequently, many teacher training colleges and universities have not prepared teachers for this huge task. Suppose all student teachers had taken English as a compulsory subject and had been taught how to apply it as prescribed in the strategy for teaching English across the curriculum [1]. In that case, they may have been better positioned to handle the learning and teaching environment with confidence.

\section{Teachers' perceived strategies for applying EAC}

[68] conducted a study examining secondary school curriculum teachers' beliefs and teaching approaches to learn English as an academic language (EAL) in their classes. The findings from that exploratory case study revealed that teachers' approaches to teaching language appeared to be shaped by their disciplinary beliefs and pedagogical content knowledge. This suggests that teachers cope with teaching language and content according to what they believe could assist learners in understanding subject content. An example of how teachers cope with EAC is code-switching. With the understanding that their learners have inadequate English knowledge and proficiency, teachers resort to code-switching in the classroom. [38] and [69] defined code-switching as switching from one language to another over phrases or sentences. 


\section{Theoretical Framework}

It is important to note that the EAC strategy cannot succeed without the commitment and cooperation of English teachers, content subject teachers, and learners [70]; [71]; [72]. This study is underpinned by the theory of collaboration [73]; [74]. [75] defined collaboration as a systematic process where teachers analyze and influence professional practice to improve individual and collective student results. [74] confirmed this, where he defined collaboration as a process of shared creation between two or more individuals with complementary skills to create a shared understanding that neither/none had previously possessed or could have formulated. In this study, the collaboration between English language teachers and subject teachers is crucial for teaching English across the curriculum. Not all teachers majored or specialized in English during their teacher training. It is understandable that to enhance their instruction, they need the assistance of English language teachers. [77] warned that collaboration is not just a process or a structure but that teachers must be committed to core ideas about student learning. In other words, collaboration is done for the sole purpose of advancing the interest of learners. A collaborative culture is an organisational environment where staff exchange ideas [78]. This collaborative culture occurs in three forms [79]:

- Organisational events and ceremonies

- During the exchange of ideas and experience

- Analysing of teaching practice

In the context of this study, a collaborative culture only manifests itself where teachers engage with one another, exchanging their teaching ideas and experience. However, in all collaborative activities, the three basic features of collaboration must prevail, i.e., trust, openness, support, and help [79]:

- Trust - the relationship of trust is vital to an effective collaborative culture. Teachers seeking the support of others should trust that they will not consider themselves as super and more intelligent A relationship of trust should help teachers overcome such fears of snobbery. Participants in the collaborative culture must overcome fear and engage in conversations about the school's core values, purpose, and vision [77].

- Openness - teachers in need of support should be open to new ideas and should be able to freely express their misunderstandings. Teachers should understand that they cannot know everything and acknowledge their shortcomings.

- Support and help - the main idea of collaboration is to provide support and help. No teacher should work in isolation while there are other teachers at school. A collaborative culture seeks to end a problem of isolation. Isolation does not allow teachers to interact with each other [80]. While teacher collaboration could be a useful tool to promote teaching English across the curriculum, it does have its shortfalls.

- Collaboration increases teacher efficacy, professional development, and learning opportunities, responsibility for work, reflection on instructional practice, and reduces work overload [81].

- It offers opportunities for teachers to make networks of relationships, which can help them share their reflective experience, evaluate beliefs on teaching and learning, and construct knowledge together [82].

- It is the main element of teacher development [83], [84], [85].

- Teachers' knowledge and experience are diffused, and instruction is enhanced [86].

- It makes teachers feel more committed to their school and teaching [87].

- It is a way to stop teacher isolation [88].

[81] discussed several negative aspects of collaboration. He categorized these aspects under four modes, i.e., conformist, contrived, co-optative, comfortable, and complacent:

- Conformist mode - an attitude that forbids working in solitude and monopolises ideas.

- Contrived mode- a collaboration controlled by the administration, rendering teachers to work without desire and inefficiently.

- Co-optative mode - where teachers must achieve the goals set by others.

- Comfortable and complacent- where teachers usually work together, share resources, and provide moral support, working practice is very flexible but not properly organized. 
[82] asserts that collaboration leads to work intensification, loss of autonomy, interpersonal conflicts, and factionalism. We do not think that collaboration is coercive by nature. It is a voluntary effort by individuals to share with and complement one another for the benefit of the learners. Instead of intensifying the work [82], collaboration eases the workload and improves teacher morale. In collaboration, teachers share the responsibility of educating some or all learners in a classroom [89].

\section{Methodology}

The three research questions linked to this paper are:

(a) What are teachers' experiences of the EAC strategy in rural secondary schools?

(b) How do teachers experience the EAC strategy in rural secondary schools? and

(c) Why do they experience it that way?

Since the purpose was to explore teachers' experiences of the EAC strategy in rural secondary schools, the study adopted a qualitative approach. The qualitative approach to research is a unique grounding that fosters particular ways of asking questions and thinking through problems [90]. [91] believes that qualitative research is interpretive and that it focuses on gaining meaning and understanding and building concepts and theories. We secured willing teachers from three schools from different circuits (three per school). We selected male and female teachers with varying teaching experience and are currently teaching in the FET phase. These teachers constituted a representative sample of rural secondary school teachers in the iLembe District.

In the study, we used interviews to generate data. Interviews depend a lot on establishing rapport with the study participants. [92] explained that the interview is a social way to share information between the interviewee and the interviewer. We used interviews to generate data to understand teachers' experiences of the EAC strategy in rural secondary schools. [93] suggest that interviews are flexible, accessible, and intelligible, and, more importantly, they are capable of disclosing essential and often hidden facts of human and organizational behavior. Nine teachers, three per school, were interviewed in their respective settings. These teachers were sampled based on their teaching experience in a secondary school and their willingness to participate.

Qualitative data analysis is an inductive process of organizing data into categories and identifying patterns [94]. We used qualitative content analysis to analyze the data. [95] explained that content analysis is a method that may be used with either qualitative or quantitative data, in either an inductive or a deductive way. We specifically used an inductive way. An approach based on inductive data moves from the specific to the general so that particular instances are observed and combined into a larger whole or general statement [96].

The organization is at the heart of qualitative data analysis [97]. [91] asserted that the processes and procedures used to analyze data provide some level of explanation, understanding, and interpretation. In this study, mindful of [98] data analysis steps, we organized and prepared data for analysis by transcribing voice-recorded interviews. A third party did the transcription. We then familiarized ourselves with the data by reading and rereading the transcripts to obtain a general sense of the information. Using the interview schedule as a guide, we related participants' responses to the interview questions and, in tabular form, allocated each response to the relevant column. This helped clarify what was said by different interviewees in response to certain questions, and it enabled us to make a general comment about their responses. We then began the process of coding. Coding is a way of indexing or categorizing the text to establish a framework of thematic ideas about it [99]. As our provisional organizing of the data, we organized the material into segments of text to attach meaning to the information and allocate topics, which would later be abbreviated as codes. We were then able to form categories of meaning from the coded topics. Having analyzed the data into categories of meaning and have organized them into main themes, we were able to identify patterns and relationships in the informants' responses.

A signed letter of informed consent was obtained from all willing participants. Informed consent is achieved by providing subjects with an explanation of the research, an opportunity to terminate their participation at any time with no penalty, and full disclosure of any risks associated with the study [94]. [100] suggested that researchers give a thorough description of their research context and the assumptions central to the research. The contents of the letter were read to the participants, explained in detail, and obtained their signatures.

\section{Research Findings}

Participants' understanding of the concept of EAC One participant out of the nine participants show clear understood of what EAC entails:

Avoca: It is a good idea to go deeper into the subject, teaching them reading and other English language aspects. When you do that, learners become more familiar with English concepts used in the examination. 
The rest of the participants ranged from having a partial understanding of the concept of EAC to having a complete lack of understanding of the concept, although they were not opposed to the idea:

Satis: It means we must teach learners in English and teach them English across other subjects. It is the right thing because, in the country [South Africa], the English language is prioritized more than indigenous languages. It will not be easy to move away from using the English language.

Gumba: According to my understanding, EAC is good if we apply it. The SMT [senior management team] should have a tool to monitor if the EAC is being used daily. The SMT needs to support teachers in implementing this strategy.

Mred2: My understanding is that every teacher in the school should teach in English in one way or another.

Mshunqisi: I have often heard of this concept of English across the curriculum, and I wonder if it is a workable idea if it is going to have a positive impact in terms of the increase in pass percentage [raising the pass percentage] of our learners, because, in the end, the important thing is the pass percentage.

Lilo: It should start at lower grades, not at secondary school.

Only one participant was completely not in favor of the Department of Education's EAC strategy:

Nono: So, the department is forcing us, even though [although] if we can allow them to come and see the situation we are teaching under, maybe they will change.

About $90 \%$ of the participants did not clearly understand what EAC is and what it entails. One participant indicated that the senior management team (SMT) has a pivotal role in implementing the EAC strategy. She stated that the SMT should have a tool to monitor if EAC is being applied daily and that they need to support teachers in implementing the strategy. I think the SMTs also need to be empowered with above-average management skills and adequate information regarding the EAC strategy to provide support and guidance to educators.

\section{Reasons for non-implementation of the EAC strategy}

The participants cited various reasons why fellow teachers are not implementing the strategy of EAC, namely the following:
- Learners' inability to use English.

- Teachers' inability to express themselves properly in English.

- Learners' home environment and

- Lack of commitment to the Department of Education (DoE).

In the following subsections, we discuss the above reasons in detail.

\section{Learners' inability to use English}

Two participants thought that teachers are not using the EAC strategy because learners are not familiar with English:

Satis: No. For example, I am not honest [I do not apply the EAC strategy faithfully] because of the situation I find myself in when I am in class. I know that if I try to be honest with EAC [if I try to apply EAC faithfully], not one of them will pass.

Nono: To answer that, no, because they are not because, as I've said, you end up talking alone if you are just implementing this EAC. Then you see that the learners are lost. So, to produce good results, you have only to use their mother tongue [you have to use only their mother tongue], so we can accommodate them.

Learners' inability to use English successfully arises from their rural background, with no Englishspeaking people. [101] maintained that if children learn to read and write, they need adult role models and literate role models. Learners use their home language most of the time, without any motivation from their parents to use the school language. Almost $99 \%$ of rural school learners resided near their school before they began schooling. This makes it difficult for them to adapt to the second language. They need dedicated and enthusiastic teachers to help them cope with English language instruction.

\section{Teachers' inability to express themselves properly in English}

Four participants thought that the problem stems from teachers being unable to express themselves in English:

Avoca: They are capable, but they are not implementing it. People tend to do something they are comfortable with. Teaching using code-switching is suitable for teachers, but they will do it perfectly if there is some pressure for them to apply [EAC]. 
Gumba: No, teachers teach A to Z in isiZulu [Zulu]. They do not even try to code-switch to English. However, this deprives our learners of understanding English, the exam language.

Mred2: I am not too sure if everybody is implementing it, but what I can say is when it comes to our teachers, one of the reasons that teachers find themselves teaching in isiZulu and not being able to apply this EAC is because most of them cannot hold a conversation in English.

Zee-code: I do not think most teachers, or all teachers can implement such strategies. One of the factors we do not address mostly is that some educators have a problem speaking proper English. They only use the language when they teach. After teaching, they do not use the language. Hence, language development is not up to the level where we can say that implementing such strategies could be easy.

Having teachers who cannot correctly express themselves in English is a factor that is neglected in terms of teaching through English. The teachers that were interviewed had a good command of the language, and they were adamant about opting for English as the language of speaking. However, the fact remains that other teachers cannot speak correct English. Language is very important in teaching since it is the vehicle through which teachers deliver subject content. [64] Many teachers do not know how to teach English as a subject, nor can they speak well enough to be effective role models of the language. If this is the case, how do such teachers teach learners in English?

\section{Learners' home environment}

Two participants mentioned that the learners' home environment plays a role in the applicability of EAC. They were of the view that whatever teachers try to do in terms of implementation of the strategy, the environment in which learners find themselves will remain a problem:

Mshunqisi: We are trying our best to implement the strategy, but it is just not taking off. It still looks like it is a futile exercise for now, but we are trying. The environment will remain a barrier.

Lilo: No, they are not implementing it around the area where I am working. They use 10\% English and 90\% isiZulu. Even if you like to use the English language in most of your teaching, you cannot work because of the environment.

The participants alluded that the environment in which learners find themselves is full of people who do not speak the language used at school, where educational resources such as libraries are nonexistent, and parents are not literate enough to help their children with their schoolwork.

\section{Lack of commitment on the part of the Department of Education}

Only one participant of the nine participants mentioned that the Department of Education is not doing enough to make the strategy take off:

Small: No, even myself, I do not understand the concept. I think other teachers are not using EAC. I believe a lot is supposed to be done about this concept. Teachers still need to be workshopped thoroughly.

The participant highlighted that the Department of Education has a big role in implementing the EAC strategy in rural schools, ensuring that teachers are familiar with the strategy, and providing ongoing monitoring and support.

\section{Discussion}

English only? One of the findings that emerged from the data was learners' inability to understand English. This inability to understand English also led to the underachievement of learners. The first theme that emerges from the findings is "English only?" In other words, is it beneficial to have an English-only approach to the curriculum? [103] stated that learners find listening comprehension difficult because they are left behind to determine what a previous word meant. They do not know the most important words, do not recognize the words they know, and have problems with different accents. This was confirmed by most of the teachers in my study. They highlighted that learner's manifest discomfort and difficulty when it comes to comprehending texts that are presented in English.

Except for the subject Zulu, all school subjects must be taught in English in South African schools. In their respective communities, learners use the vernacular language most of the time, and there is no chance of practicing English. There are also no English-speaking role models for them to imitate. English is alien for many rural school learners, which poses a problem for them when they must assimilate academic information presented in English. There are two opposing solutions to this problem. One way is for teachers to continually teach in English, irrespective of whether learners understand, until learners get used to the language and start comprehending it. The other way is that teachers should just juggle between English and Zulu to facilitate comprehension. Both solutions create even more problems for learners. The problem with the first option is that it may take a very long time for learners to get used to English and start 
comprehending it. They would have lost considerable chunks of information relating to a certain subject when they began to comprehend English. This method could also lead to regurgitation, where learners swallow information, as it were, without any digestion of facts. The second option is also problematic in that, although it facilitates quick comprehension, it does not guarantee success in the relevant subject assessments because learners are expected to complete their assessments through the medium of English.

Furthermore, examination rules dictate that candidates may not be assisted in any way that might jeopardize the integrity of the examinations, including interpreting questions for them. As a result, many learners fail assessments, even when they understand the subject because they must respond in English. Sometimes they misunderstand the question and fail to give an appropriate response. Therefore, it is correct to suggest that learning English, not their mother tongue, really poses comprehension problems.

Practicing English at school could be the right option. Still, there is no motivation to do so since our country's constitution stipulates that every South African citizen can use their mother tongue and give or receive information through it. The language issue is further complicated by some teachers' lack of proficiency in using English. The second theme that emerged from the findings is the language conundrum for teachers.

\section{The language conundrum for teachers}

[102] argued that many teachers do not know how to teach English as a subject, nor can they speak well enough to be effective role models of the language. Although many people may find this interesting, some teachers are not good at using English. Two of the interviewed teachers mentioned that teachers themselves have a problem interacting with learners in English. To these teachers, codeswitching is not just a way of helping learners understand, but it is a more comfortable way to conceal their lack of English language proficiency. The participants in our study mentioned that teaching using code-switching is convenient for teachers.

Many of our rural school educators live in communities dominated by Black people who speak only African languages. Teachers, just like learners, encounter English during teaching periods; after that, they revert to their vernacular. This deprives them of the chance to grow in English language proficiency. English is part of the teacher training curriculum at colleges and universities. The assumption is that increasing teachers' general capacity in the language may lead to improved classroom teaching and student learning [104]. However, not all teachers have a good command of English. Therefore, teachers' consistency in applying EAC varies according to individual teachers' proficiency in English. So, if teachers have problems with English, it is hard for them to become effective role models of the language. [105] argued that if teachers are not conversant in English, how can a nation expect learners to receive standard education? Language is very important in acquiring knowledge, as it is the vehicle through which knowledge is transmitted. Transmitting knowledge to another person so that they ultimately own that knowledge is a huge task. This task becomes more complicated if the language of transmission is not the teacher's vernacular language. The mother tongue is essential for learning as a part of intellectual ability, and it helps the child in their mental, moral, and emotional development [106]. Distortion and misrepresentation of information can result if the one transmitting knowledge is not thoroughly conversant in the language of transmission. The EAC strategy relies not only on teachers' proficiency in English but also on the four aspects of teaching language effectively, namely listening, speaking, reading, and writing. Teachers who teach English as a subject understand the importance of applying these aspects, but unfortunately, these teachers are few.

The findings also showed that learners' home environment is a challenge to implementing the English Across the Curriculum strategy. The third theme discussed in this section is learners' unfavorable home environment. We have named this theme "English begins and ends at school."

\section{English begins and ends at school}

Language, culture, and the environment are interdependent [51]. This means that learning another language means learning another culture [107]. Rural school learners are not exposed to the culture of English language speakers. This makes it practically difficult for them to assimilate English culture, thus proficiency in using English. Learners' environment and culture have a beneficial influence on language acquisition. [33] argued that without language, no transfer of culture between generations is possible, as parents or caregivers communicate to their children the cultural values that underlie language. Learners only use English while they are at school. Learners do well in the subject Zulu because Zulu is the language used in their homes and communities. For the EAC strategy to succeed, learners' environment should be supportive and complementary. As some teachers highlighted in my study, rural school learners' home environment is unfavorable for implementing the EAC strategy. Firstly, learners' family members and community members do not speak the school language. [108] suggested that parents should be active partners in their children's education. If they are empowered, 
this means that parents should assist their children by talking to them in the school language. Secondly, people living in rural areas often have little or no access to libraries and bookshops [109]. Thirdly, cultural and religious practices are performed in the home language. In other words, learners are deeply immersed in the context of their Zulu home language. The environment plays a crucial role in the acquisition of knowledge. Put differently, the environment and cognitive development go together. [110] believed that the environment in which children grow up will influence how they think and think. Environmental influences inevitably include culture. The problem with our rural school learners is that the school culture and the home culture are not the same. In rural communities, the illiteracy rate is very high. Very few parents can assist their children with homework and speak to them in the school language. There are also no English language books, newspapers, magazines, and pamphlets that learners can familiarize themselves with English.

In most cases, learning in English begins and ends at school. At home, there is no motivation to engage in the language of instruction. In short, learners' home environment lacks the infrastructure to promote effective learning. Many households do not have a television or even a radio. Those who have these devices share them with other family members, and, to accommodate everyone, programs presented in Zulu are favored. In such an environment, learners' chances of becoming familiar with the school language are minimal.

Another theme that emerged from the findings was the Department of Education's involvement (or, to be precise, noninvolvement). This theme is called "Is it a case of the carelessly lazy Department of Education?"

\section{Is it a case of the carelessly lazy Department of Education?}

The role of the Department of Education in the implementation of the EAC strategy cannot be overemphasized. The department seems to be dragging its feet to make the strategy work. Three of the nine teachers that were interviewed showed that they did not understand the concept of EAC. The remaining six teachers had heard about the concept from others. This could imply that the Department of Education may have ignored the essential part of conducting ongoing meetings and workshops to sufficiently unpack the strategy.

Teachers are the implementers of the curriculum, education legislation, and directives. Therefore, it is essential to get them on board with new developments in education to be able to implement changes judiciously and meaningfully. [111] wrote:
Without a doubt, the most important person in the curriculum implementation process is the teacher. Teachers are central to any curriculum development effort with their knowledge, experiences, and competencies. Better teachers support better learning because they are most knowledgeable about teaching and are responsible for introducing the curriculum in the classroom.

Once something relating to education has been legislated, it becomes the responsibility of the Department of Education to ensure that procedures and processes are put in place to advocate, monitor, and control its implementation. The department should also support relevant school infrastructure, e.g., language laboratories, libraries, audiovisual devices, etc. The department should seek feedback from teachers regarding implementing the strategy, with the view to restrategizing to obtain better outcomes. Such feedback should be goal-referenced, tangible and transparent, actionable, user-friendly, timely, ongoing, and consistent [112]. The Department of Education is duty-bound to enhance teaching and learning by ensuring improved curriculum delivery, promoting equitable access to learning, and equipping schools with adequate support material of good quality. [113] stated that teaching and learning materials are vital for teaching and learning to take place effectively in the classroom.

The Education Department is currently operating under strict budget constraints. Officials to monitor, evaluate, and support are inadequate, and finance to fund their travel from school to school is limited. According to [114], monitoring and evaluation are meant to influence decision-making, including decisions to improve, reorient, or discontinue the evaluated intervention or policy, wider organizational strategies or management structures, and national and international policymakers' decisions regarding funding agencies.

\section{English as an alien language}

In most iLembe rural communities, English is never spoken. The commonly spoken language is Zulu, which is the language of their culture. They perform rituals and various traditional ceremonies, which inevitably include singing, ululating, clan praises, and other activities through the medium of Zulu. English is alien to their culture. Those with radios listen to radio stations where broadcasts are done in Zulu. Most of our learners play maskandi music or kwaito on their smartphones, and their favorite newspapers are Ilanga and Isolezwe. Given this scenario, learners experience difficulty at school 
when they must engage in English. Very few learners cope with English as a medium of instruction; most rely on teachers' code-switching to the vernacular. It is a completely different scenario in urban areas since different race groups use English as a medium of communication. This is because cities are hubs of commerce and business. English is now the global language of business [63]. Therefore, mixing with these race groups gives an urban school learner an advantage over a rural school learner. Of the participants in my study, $67 \%$ thought that language is a factor that causes a disparity in performance between Black and White and Indian counterparts.

[115], a study of demographic factors affecting students' academic performance noted that if the language of teaching and learning coincides with its home language, one might expect it to be an advantage. One of the participants, Gumba, stated that his learners use their home language everywhere in their community. If they were to learn all subjects in the language they use in their community, they could perform better in their assessments. This suggests that it would be more desirable for learners to receive instruction in the widely spoken language in their home environment.

\section{Literacy goes beyond reading and writing}

Illiteracy plays a negative role in the interaction between parents and their school-going children. The more literate a parent is, the more conscious they will be of the role education can play in their child's life. [116] stated that parents' educational level strongly influences children's academic success. As noted by one of the participants, Nono, White people, who are presumably literate, encourage their children to study and even pay for extra classes.

Literacy goes beyond being able to read and write. UNESCO, in [117], noted:

\section{A person is literate when he has acquired the essential knowledge, which enables him to engage in all activities in which literacy is required for the effective functioning of his group and community and where attainment in reading, writing, and Arithmetic makes it possible for him to use these skills towards his own and community's development.}

This implies that literate parents or adult community members can support and encourage their youth in education. Supporting a school-going child could mean conversing with them in the school language to help them become conversant in it. This calls for a conscious effort by the Department of Education to promote a vigorous family literacy program to assist illiterate families. [115] suggested that a family literacy program will generally have three components: literacy for children, literacy for parents, and guidance for adults on encouraging the literacy skills of their children or young relatives.

In the iLembe District, rural community illiteracy is a huge problem. According to Census 2001, the illiteracy rate for Ndwedwe Local Municipality was $24 \%$, for Maphumulo Local Municipality, it was $27 \%$, and for Stanger Local Municipality, it was 14\%. Stanger Local Municipality recorded a low illiteracy rate because it consists mostly of urban and semi-urban areas. In urban areas, parents even communicate with form teachers through parent communication books to discuss learners' problems, achievements, and areas for parental intervention.

\section{Lack of comprehensive monitoring and evaluation of the EAC strategy}

Monitoring and evaluation form the basis for any strategy's effective and efficient implementation. These are critical tools for forward-looking strategic positioning, organizational learning, and sound management [114]. It should not be a once-off undertaking, but it should be ongoing and be accompanied by support interventions where possible. As an educator in a secondary school, one of the authors has observed no monitoring and evaluation of the EAC strategy. This makes it tempting for educators and even senior management teams (SMTs) to undervalue the strategy. It is then left to the conscience of each teacher to do justice to the strategy in their teaching. The SMT conducts class visits to manage the quality of teaching through the Integrated Quality Management System (IQMS). On the day of the class visit, the teacher makes sure that they present their lessons through instruction only. With an understanding that many learners are left behind when only English is used, teachers must often conduct repeat lessons, where they code-switch to the learners' vernacular. There is also no monitoring tool to check if teachers or schools are implementing the EAC strategy. Such a tool would give the Department of Education an idea of what is happening in schools in terms of the strategy. The tool would also serve as a reminder for teachers to continue to apply the strategy.

\section{Lack of advocacy campaigns}

Advocacy campaigns are crucial for any undertaking to take off. [114] defines advocacy as the active support of an idea or cause expressed through strategies and methods that influence the opinions and decisions of people and organizations. He adds that advocacy creates or changes policies, laws, regulations, distribution of resources, or other decisions that affect people's lives and ensure that such decisions lead to implementation. Among the 
teachers that were interviewed, some were completely unaware of what the EAC strategy entails. This means that the Department of Education may have failed to embark on a vigorous advocacy campaign across the whole country. As part of advocacy campaigns, the department should also have conducted question and answer sessions to resolve all ambiguity and uncertainty regarding the strategy. In the iLembe District alone, there has never been a conscious effort to spread the message of the EAC strategy. The iLembe District randomly conducted meetings on the EAC strategy in the initial stages of campaigning. However, the enthusiasm to pursue the campaign waned as time went by.

\section{Recommendations}

Our research focused on applying the EAC strategy in rural schools, where urban and township schools consisting of learners from predominantly Black African communities were excluded from the sample. Future studies could include urban and township schools with learners from predominantly Black African communities. Secondly, our research was limited to rural secondary school teachers' experiences of the EAC strategy. It would give a broader picture of the EAC strategy in rural schools if the experiences of rural secondary school learners were included in future studies.

\section{Conclusions}

The previous section dealt mainly with the themes relating to the study. This section will specifically provide a way forward for future researchers and policymakers. The conclusion and recommendations will be presented based on the findings.

Teachers do not adhere to the EAC strategy because learners have a big challenge understanding English. Therefore, we recommend that schools and teachers foster continual use of English by learners during school hours. Practicing English daily will ultimately enable learners to become familiar with and conversant in the target language of learning and teaching. Teachers should assist learners by teaching them some often-used phrases, such as asking for permission to leave the class, apologizing for coming late, etc. We further recommend that teachers help learners by providing sufficient reading material, which should, as a traditional principle, range from simple to complex in difficulty level. If learners are exposed to reading material presented in the target language, they will ultimately become familiar with the language. [120] believe that, since literature plays an essential role in foreign language acquisition, each level of foreign language study requires the inclusion of literary texts.
Teachers do not use the EAC strategy faithfully because they have a problem using English. In this regard, we feel that special workshops and training sessions addressing teachers' inadequacy and inefficiency in using English should be conducted in all the rural parts of the country. If teachers, who should be the driving force behind the EAC strategy, are found lacking in English language proficiency, the strategy will be a nonstarter. [101] stated that children must interact with people who know the language. Teachers should dedicate some of their free time to engaging with English literature and media. In terms of the Department of Education's Professional Development Portfolio (PDP) initiative, teachers are expected to engage in self-development programs and activities with the ultimate aim of improving their teaching expertise. The recommendation above could form part of teachers' Professional Development Program and help make teachers effective role models of the target language.

The EAC strategy is not functional because the Department of Education has not committed itself to it. The Department of Education should take decisive measures to revitalize the EAC strategy. One way of doing this would be to deploy more staff to evaluate and monitor the functionality of the EAC strategy in rural schools. Retired language teachers could be reemployed to drive the strategy. School management teams should pay regular visits to classes with the sole purpose of ensuring that teachers are teaching English across the curriculum and are doing it in the right way.

\section{References}

[1] Department of Education. (2019). Teaching English Across the Curriculum. https://www.education.gov.za/Tea chingEnglish.aspx. (Access Date: 23 September 2021).

[2] Fan, Y. (2013). Every teacher is a language teacher: Preparing teacher candidates for English language learners through service-learning. Gateways: International Journal of Community Research and Engagement, 6, 77-92.

[3] Stander, M. (2001). Taaloordrag in die onderrig van Afrikaans as tweede taal. Literator: Journal of Literary Criticism, Comparative Linguistics and Literary Studies, 22(3), 107-122.

[4] Collier, V., and Thomas, W. (2012). English language learners. What every principal needs to know to create equitable and excellent schools, 155-173.

[5] Murenga, S. T. (2017). Perceptions and Views of the Impact of the Department of Basic Education and Nongovernmental Organisation Intervention Programs in Rural Schools in Relation to Matric Results. University of Johannesburg (South Africa).

[6] Clark, U. (2018). Developing language and literacy in English across the secondary school curriculum: An inclusive approach. Springer. 
[7] Mpofu, N., and Maphalala, M. C. (2020). What counts as disciplinary literacy instructional approaches in teacher education? TD: The Journal for Transdisciplinary Research in Southern Africa, 16(1), 1-7.

[8] Ntombela, S. A. (2019). Nicknaming among the Zulu: the case of naming medicinal plants. Nomina Africana: Journal of African Onomastics, 33(1), 47-59.

[9] Statistics South Africa. (2015). http://www.statssa.gov. $\mathrm{za} / \mathrm{m}=2015$. (Access Date: 11 November 2021).

[10] Othman, J. and Saat, R.M. (2009). Challenges of Using English as a Medium of Instruction: Preservice Science Teachers' Perspective. The Asia-Pacific Education Researcher 18 (2): 307-316. DOI: 10.3860/taper.v18i2.13 31.

[11] Aghai, L., Sayer, P., and Vercellotti, M. L. (2020). Effects of teachers' language ideologies on language learners' translanguaging practices in an intensive English program. In Z. Tian, L. Aghai, P. Sayer, and J. L. Schissel (Eds.), Envisioning TESOL through a translanguaging lens: Global perspectives (pp. 345-362). Springer.

[12] Probyn, M. (2001). Teachers' voices: Teachers' reflections on learning and teaching through the medium of English as an additional language in South Africa. International Journal of Bilingual Education and Bilingualism, 4(4), 249-266.

[13] Maluleke, M. J. (2019). Using code-switching as an empowerment strategy in teaching mathematics to learners with limited proficiency in English in South African schools. South African Journal of Education, 39(3).

[14] Marawu, S. (2018). Teaching in two languages: The pedagogical value of code-switching in multilingual classroom settings. In P. van Avermaet, S. Slembrouck, K. van Gorp, S. Sierens, and K. Maryns (Eds.), The multilingual edge of education (pp. 93-113). Palgrave Macmillan

[15] Obrocka, M., Copley, C., Gqaza, T., and Grant, E. (2019). Prevalence of code mixing in semi-formal patient communication in low resource languages of South Africa. arXiv, 1911(05636v3), 1-4. On-line version ISSN 2076-3433.

[16] Songxaba, S. L., Coetzer, A., and Molepo, J. M. (2017). Perceptions of teachers on creating space for code switching as a teaching strategy in second language teaching in the Eastern Cape province, South Africa. Reading and Writing, 8(1), 1-7.

[17] Mati, X. (2004). Using code switching as a strategy for bilingual education in the classroom.

[18] AlHarbi, M.S. (2018) Exploring English language teaching approaches in Saudi Higher Education in the West Province. PhD thesis.

[19] John, Y. J. (2015). A" New" Thematic, Integrated Curriculum for Primary Schools of Trinidad and Tobago: A Paradigm Shift. International journal of higher education, 4(3), 172-187.
[20] Zama, C.Z. (2014). Teachers' experiences of teaching first additional language reading in the foundation phase: a case study of four rural primary schools. UKZN.

[21] Dlangalala, N.T.Q. (2000). Analysis of the high matric failure rate in rural schools. M.Ed. dissertation. Johannesburg: Rand Afrikaans University.

[22] Bharuthram, S. (2012). Making a case for the teaching of reading across the curriculum in higher education. South African Journal of Education, 32(2), 205-214.

[23] Ferllazzo, L. (1998). "Building A Community Of Self-Motivated Learners: Strategies To Help Students Thrive In School and Beyond" Routledge.

[24] Godson, L. (1994). Vowel Production in the Speech of Western Armenian Heritage Speakers. Heritage Language Workshop.

[25] Ughamadu, D. (2006). Higher Education and Human Capital Development in Nigeria: Issues and challenges to Actualising Vision. Oral Proficiency for Visual Arts Students, 158.

[26] Mulenga, I. M. (2018). Conceptualization and Definition of a Curriculum.

[27] Steiner, D. (2017). Curriculum research: What we know and where we need to go. The Constitution of the Republic of South Africa (Act 108 of 1996).

[28] Makhele, E. (2018). A Conceptual Framework For a Decolonized and Africanized Curriculum. International Journal, 74(11/1).

[29] Wei, R., \& Su, J. (2012). The statistics of English in China: An analysis of the best available data from government sources. English Today, 28(3), 10-14.

[30] Stuart, N J. (1989). Pit optimization in the Prolog computer language. Canada: N. p., Web.

[31] Popper, K. R., \& Eccles, J. C. (1977). The Language Centres of the Human Brain. In The Self and Its Brain (pp. 295-310). Springer, Berlin, Heidelberg.

[32] Maphalala, J. (2000). Public policy and African languages: the case of IsiZulu, Pp148- 156. In Du Plessis, T. and Deprez, K.A.S. (2000) (eds). Multilingualism and Government. Pretoria. Van Schaik.

[33] Du Plessis, S., and Louw, B. (2008). Challenges to preschool teachers in learner's acquisition of English as Language of Learning and Teaching. South African Journal of Education, 28, 53-75.

[34] Cuvelier, P., du Plessis, T., Meeuwis, M., Vandekerckhove, R., Webb, V. (Eds). (2013). Multiling ualism for Empowerment. Pretoria. Van Schaik.

[35] Bharuthram, S. (2012). Making a case for the teaching of reading across the curriculum in higher education. South African Journal of Education, 32(2), 205-214.

[36] Grobler, R. (2018). Students' Perceptions of CodeSwitching in Natural Sciences Classrooms: A South 
African Perspective. Africa Education Review, 15(1), 3851.

[37] Foley, A. (2001). Mother-tongue education in South Africa teachenglishtoday.org.

[38] Lawrence, D.C. (1999). Kodewisseling: Engels in Afrikaans - ' $\mathrm{n}$ instrument tot effektiewe kommunikasie. SAALT Journal for Language Teaching, 33, pp. 265- 274.

[39] Owens, D. (2001). Composition and Sustainability: Teaching for a Threatened Generation. Refiguring English Studies. National Council of Teachers of English, 1111 W. Kenyon Road, Urbana, IL 61801-1096 (Stock No. 003761659; members, \$23.95; nonmembers, \$33.95).

[40] Milin, T. \& Milin, M. (2017) English academic writing convergence for academically weaker senior secondary school students: Possibility or pipeline dream? Elsevier Ltd. South Africa.

[41] Cook, M.J. (2015). South Africa's mother tongue challenge. (online) (2015/09.05).

[42] Sibiya, A.T. (2014). Language crucial in SA transforming education. Dispatch Live.

[43] Cook, V. (1999). Beyond the native speaker in language teaching

[44] Met, M. (1998). Critical issues in early second language learning: Building for our children's future. ERIC.

[45] Ambert, A.N. (1988). Bilingual Education and English as a Second Language. Garland. London. New York.

[46] Christian, C.C. (1976). Social and psychological implications of bilingual literacy pp17 - 40. In Simoes, A. (Ed). The Bilingual Child. New York. London.

[47] Parlakin, R. (2003). Before the ABCs: promoting school readiness in infants and toddlers. Washington DC: Zero to Three.

[48] Lee, O., Luykx, A., Buxton, C., \& Shaver, A. (2007). The challenge of altering elementary school teachers' beliefs and practices regarding linguistic and cultural diversity in science instruction. Journal of Research in Science Teaching, 44 (9), 1269-1291.

[49] Guskin, J. T. (1976). what the child brings and what the school expects: first and second language learning and teaching in bilingual- bicultural education. In Simoes, A. (Ed). The Bilingual Child. New York. London.

[50] Hybels, S. and Weaver II, R.L. (2004) Communicating effectively. New York. Foley, A. (2001). Mother-tongue education in South Africa. Teachenglishtoday.org. McGraw Hill inc.

[51] Blackledge, A. (Ed.). (1994). Teaching bilingual children. Trentham.
[52] Lanshear, C. with Gee, J.P., Knobel, M. and Searle, C. (1997). Changing literacies. Great Britain. Lindsay Ross International Ltd.

[53] Mercuri, S., \& Ebe, A. E. (2011). Developing academic language and content for emergent bilinguals through a science inquiry unit. Journal of Multilingual Education Research, 2 (1), 6.

[54] WA Thiong'o, N. (1986). Decolonising the mind: The politics of language in African literature. Zimbabwe publishing house. Harare.

[55] Spiteri, D. (2019). English for all: Repositioning English across the curriculum. Malta Review of Educational Research, 13 (2), 194-208.

[56] Rautenbach, E., Olifant, T., and Cekiso, M. (2019). Teachers' perceptions of Grades 8-10 English First Additional Language learners' reading habits, attitudes and motivation. Reading and Writing-Journal of the Reading Association of South Africa, 10 (1), 1-11.

[57] Habeeb, K. (2013). Teachers' Perceptions toward Implementing English as a Foreign Language at Kindergarten: What Can We Learn from the Case of Kuwaiti Kindergarten Teachers? University of Arkansas.

[58] Marungudzi, T. (2009). English as a language of learning and teaching: perspectives of secondary school teachers in the Masvingo District (Zimbabwe) (Doctoral dissertation, University of South Africa).

[59] Skinnari, K., and Nikula, T. (2017). Teachers' perceptions on the changing role of language in the curriculum. European Journal of Applied Linguistics, 5 (2), 223-244.

[60] Anyiendah, M. S. (2017, May). Challenges faced by teachers when teaching English in public primary schools in Kenya. In Frontiers in Education (Vol. 2, p. 13). Frontiers.

[61] Correll, P. K. (2016). Teachers' preparation to teach English language learners (ELLs): An investigation of perceptions, preparation, and current practices. University of Kentucky.

[62] Morrell, P. D., Hood, S., and Mellgren, E. (2019). A first-year middle school science teacher's experiences navigating science content in a Dual Language Immersion Program. Heliyon, 5 (10), e02575.

[63] Neeley, T. (2012). Global Business Speaks English. South African Journal of Education.

[64] Posel, D. and Zeller, J. (2016). Language shift or increased bilingualism in South Africa: Evidence from census data. Journal of Multilingual and Multicultural Development, 37 (4), 357-370. DOI: 10.1080/01434632.2 15.1072206

[65] Roman, S. P. (2004). Illiteracy and older adults: Individual and societal implications. Educational gerontology, 30 (2), 79-93. 
[66] Van Rooyen, D., and Jordaan, H. (2009). An aspect of language for academic purposes in secondary education: complex sentence comprehension by learners in an integrated Gauteng school. South African Journal of Education, 29 (2), 271-287.

[67] Manditereza, B. (2014). Improving quality of pedagogical practices in English as a language of learning instruction. Interim: Interdisciplinary Journal, 13 (1), 4052.

[68] Gleeson, J. (2012). The professional knowledge base and practice of Irish post-primary teachers: what is the research evidence telling us? Irish Educational Studies, 31 (1), 1-17.

[69] Zulu, N. (1996). Code switching or no code switching: What is the answer? SAALT Journal for Language Teaching, 30, 104-110.

[70] Mavilidi, M. F., Lubans, D. R., Morgan, P. J., Miller, A., Eather, N., Karayanidis, F., Lonsdale, C., Noetel, M., Shaw, K., and Riley, N. (2019). Integrating physical activity into the primary school curriculum: Rationale and study protocol for the "Thinking while Moving in English" cluster randomized controlled trial. BMC Public Health, 19(1), 379.

[71] Rodriguez-Yagi, M., Isemonger, I., Rupp, M. J., and Minor, D. (2019). Academic English and curriculum development: Materials evaluation under a content-based instruction (CBI) rationale. Proceedings of the School of Agriculture, Tokai University, 38.

[72] Van Van, H. (2018). MoET's three pilot English language communicational curricula for schools in Vietnam: Rationale, design and implementation. VNU Journal of Foreign Studies, 34(2), 1-25.

[73] Lughmani, S. D., Gardner, S., Chen, J., Wong, H., and Chan, L. (2016, January). English across the curriculum: F ostering collaboration. ELTWO: Special Issue on 5th CEL C Symposium Proceedings, 2016, 19-33. https://blog.nus.e du.sg/eltwo/files/2016/12/2-English-Across_Lughmani-etal-221216-1n0bntj.pdf. (Access Date: 14 November 2021).

[74] Wingate, U. (2018). Academic literacy across the curriculum: Towards a collaborative instructional approach. Language Teaching, 51(3), 349-364.

[75] DuFour, R. (2003). Leading edge: 'Collaboration lite' puts student achievement on a starvation diet. Journal of Staff Development, 24(3), 63-64.

[76] Montiel-Overall, P. (2005). Toward a Theory of Collaboration for Teachers and 7Librarians. School library media research, 8 .

[77] Ervin, S. R. (2011). The relationship between teacher collaboration and student achievement [PhD thesis]. University of Southern Mississippi, Hattiesburg, Mississippi.

[78] Hargreaves, A., \& Fullan, M. G. (1992) Understanding teacher development. Teachers College Press, 1234 Amsterdam Avenue, New York, NY 10027.
[79] Nissen, L. B. (2019). Art and social work: History and collaborative possibilities for interdisciplinary synergy. Research on Social Work Practice, 29(6), 698707.

[80] Shakenove, L. (2017). The Theoretical Framework of Teacher Collaboration. Khazar Journal of Humanities and Social Sciences, 20 (2). 34-48, Khazar University Press.

[81] Hargreaves, D. H. (1994). The new professionalism: The synthesis of professional and institutional development. Teaching and teacher education, 10(4), 423438 .

[82] Johnson, D. W. (2003). Social interdependence: interrelationships among theory, research, and practice. American psychologist, 58(11), 934.

[83] Achinstein, B. (2002). Conflict amid community: The micropolitics of teacher collaboration. Teachers College Record, 104(3), 421-455.

[84] Carol K. K. Chan \& Ming Fai Pang (2006) Teacher Collaboration in Learning Communities, Teacher Education, 17:1, 1-5, DOI: 10.1080/10476210500527899

[85] Clement, M., \& Vandenberghe, R. (2000). Teachers' professional development: a solitary or collegial (ad) venture? Teaching and teacher education, 16(1), 81-101.

[86] Burton, T. (2015). Exploring the Impact of Teacher Collaboration on Teacher Learning and Development The essential guide for teachers. Teachers College Press.

[87] Schleifer, D., Rinehart, C., \& Yanisch, T. (2017). Teacher Collaboration in Perspective: A Guide to Research. Public Agenda.

[88] Wilkinson, I. A., Reznitskaya, A., Bourdage, K., Oyler, J., Glina, M., Drewry, R., \& Nelson, K. (2017). Toward a more dialogic pedagogy: Changing teachers' beliefs and practices through professional development in language arts classrooms. Language and education, 31(1), 65-82.

[89] Nevin, A. I., Thousand, J. S., and Villa, R. A. (2009). Collaborative teaching for teacher educators-What does the research say? Teaching and teacher education, 25(4), 569-574.

[90] Hesse-Biber, S. N., and Leavy, P. (2011). The practice of qualitative research (2nd ed.). Sage.

[91] Moran-Ellis, J., Alexander, V. D., Cronin, A., Dickinson, M., Fielding, J., Sleney, J., and Thomas, H. (2006). Triangulation and integration: process, claims and implications. Qualitative research, 6(1), 45-59.

[92] Pinsky, D. (2015). The sustained snapshot: Incidental ethnographic encounters in qualitative interview studies. Qualitative Research, 15(3), 281-295.

[93] Qu, S. Q. and Dumay, J. (2011). The Qualitative Research Interview (May 14, 2011). Qualitative Research in Accounting and Management, 8(3), 238-264, 2011, 
Available at SSRN: https://ssrn.com/abstract=2058515. (Access Date: 17 November 2021).

[94] Macmillan, J., and Schumacher, S. (2010). Research in education: Evidence-based 6inquiry (7th ed.). Pearson.

[95] Elo, S. and Kyangas, H. (2008). The qualitative content analysis process. DOI: $10.1111 / \mathrm{j} .1365-2648.20$ 07.04569.x.

[96] Chinn, P. L., and Kramer, M. K. (1999). Theory and nursing: Integrated knowledge development. St. Louis: Mosby.

[97] Loue, S. (2007). Textbook of research ethics: Theory 00 and practice. Springer Science and Business Media.

[98] Creswell, J. W. (2009). Research design: Qualitative, quantitative and mixed methods approaches (3rd ed.). Sage.

[99] Gibbs, G.R. (2007). Analyzing Qualitative Data. DOI: $10.4135 / 9781849208574$. Sage.

[100] Cullen, K. A. (2014). A critical race and critical Whiteness theory analysis of preservice teachers' racialized practices in a literacy across the curriculum course (Doctoral dissertation, Syracuse University).

[101] Bloch, C. (2015). Nal'ibali and libraries: activating reading together.

[102] Cook, M. J. (2013, November 18). South Africa's mother tongue education challenge. Brand South Africa.

[103] Case, A. (2008). Why your students have problems with listening comprehension. UE using English. Com.

[104] Freeman, D. and Katz, A. (2015). English-forTeaching: rethinking teacher proficiency in the classroom. March 2015, DOI: 10.1093/elt/ccu074.

[105] Hossain, M. (2016). Advances in Language and Literary Studies ISSN: 2203-4714 Vol. 7 No. 3; June 2016 Australian International Academic Centre, Australia English Language Teaching in Rural Areas: A Scenario and Problems and Prospects in Context of Bangladesh.

[106] Noormohamadi, R. (2008). Mother tongue, a necessary step to intellectual development. Journal of PanPacific Association of Applied Linguistics, 12 (2), 25-36.

[107] Brown, H. D. (2000). Principles of language learning and teaching (Vol. 4). New York: Longman.

[108] Burnett, G. and Jarvis, K. (2004). Parents first. Parents and children learning together. Carmarthen, Wales, Williston, VT: Crown House Publishing.

[109] Mulgrew, N., 2012. 'National literacy: Once upon a time, parents taught their children to read', Mail and Guardian, 19 October, p.14.

[110] Vygotsky, L. S. (1962). Thought and language. Cambridge MA: MIT Press.
[111] Alsubaie, M. A. (2016). Curriculum development: Teacher involvement in curriculum development. Journal of Education and Practice, 7 (9), 106-107.

[112] Wiggins, G. (2012). Seven keys to effective feedback. Feedback, 70 (1), 10-16.

[113] Riet, A.M. (2012). The Use of Learning and Teaching Support Material for Classroom Teaching: Intermediate Phase. A research report submitted in partial fulfilment of the requirements for the degree of Master of Education at the University of the Witwatersrand.

[114] UNICEF. (2013). Programme Policy and Procedures Manual: Programme Operations, UNICEF, New York, Revised May 2003, pp. 109-120.

[115] Sommerville, T Singaram, V.S. (2018). Exploring demographic influences on students' academic performance over a five-year programme. South African Journal of education ome > Vol 32, No 2 (2018).

[116] Nicholas, O. and Olanike S. (2010). The Effect of Parental Education Attainment on School Outcomes. Academic Journal Article, Ife Psychologia.

[117] Hilton, M. (1998). Raising literacy standards: the true story. English in Education, 32 (3), 4-16.

[118] Train, B. 2007. Research on family literacy: an international perspective. Library Review, 56 (4):292-298.

[119] Harrison, V., Buckley, C., and Xiao, A. (2020). The roles of donation experience and advocacy: extending the organization-donor relationship model. Journal of Communication Management.

[120] Krysteva and Kukubajska. (2013). Procedia - Social and Behavioral Sciences. 